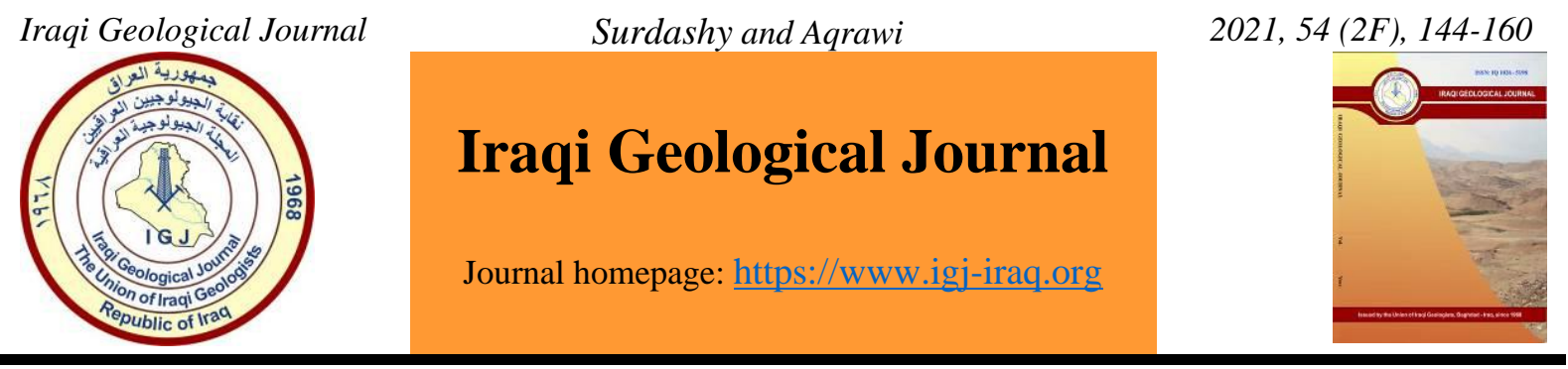

\title{
Assessment of Clay Deposits Quality from East of Erbil, Kurdistan Region, Iraq for some Ceramic Industries
}

\author{
Aveen Ali Surdashy ${ }^{1 * *}$ and Ahmed Mohammed Aqrawi ${ }^{1}$ \\ 1 Department of Geology, College of Science, Salahaddin University-Erbil, Kurdistan Region, Iraq \\ * Correspondence: Avin.mahmood@ su.edu.krd
}

Received: 12 July 2021; Accepted: 12 September 2021; Published: 31 December 2021

\begin{abstract}
For the assessment of clay deposits for brick manufacturing, seven clay samples from different locations were collected by channel sampling method from Injana, Mukdadiyah, Bai Hassan formations and Quaternary deposits in Bestana village, the study area is located east of Erbil city (NE Iraq). For ceramic manufacturing, the quality of clay should be measured according to some physical properties. The mineralogical and geochemical study revealed by using X-ray diffraction and chemical characteristics, which represented that all clay samples containing; kaolinite, smectite, illite, and chlorite with some mixed clay and non-clay mineral quartz, calcite, dolomite, and feldspar. The physical properties of clay samples including grain size analysis and Atterberg limits showed that the raw materials contain clay in high proportion, silt in medium proportion, and sand in minor proportion. Plasticity index of the studied samples showed that they are moderately plastic to plastic range. The geochemical analysis of the studied samples showed that the clay raw materials are composed mainly of silica and alumina, which act as refractory material in the ceramic industry. In addition to that, there are different proportions of calcium, iron oxides, magnesium, potassium, and sodium, which are flux oxides.
\end{abstract}

Keywords: Injana; Mukdadiyah; Bai Hassan; Quaternary; X-ray diffraction; Ceramic; Plasticity

\section{Introduction}

Clays are the main raw materials invested in the manufacturing of various ceramic products such as bricks, tiles, abrasives, pottery, porcelain, refractory (Awadh and Al-Owaidi, 2020). Clay used in ceramic industries since they can be easily molded into any form because of their plasticity, and they give hardness and strength to the ceramic body after firing, the reaction of clay with other minerals during firing including silica, other flux material like feldspar, that they are responsible in the final product properties (Kingery, 1967). There is a difficulty in studying clay mineralogy by microscope due to its small particle size $(<4 \mu \mathrm{m})$, using X-ray diffraction (XRD) are fundamental tools in clay minerals identification. Researchers have studied clay deposit suitability in various localities by applying different tests in order to assess its quality for ceramic industry. Al-Hakeem (1998) studied some clays from Neogene at north and northeastern of Iraq from Aqra, Harrir, Hamam Alil, Bastura, and Aski areas for ceramic industry. The researcher concluded that most of the clays from the selected areas were suitable for manufacturing various types of tiles and building bricks. Awad and Awadh (2020) studied reserve estimation of Late Miocene Injana claystone beds for portland cement and brick industry in Iraq determined as a proven reserve by using triangle and GIS method. Awad and Awadh (2021) and Awadh and Awad (2021) manufactured perforated and ordinary bricks using injana claystone in Karbala-Najaf

DOI: 10.46717/igj.54.2F.13ms-2021-12-30 
plateau in the middle of Iraq, the researchers concluded that Injana claystone is suitable for such purposes. Najim and Yousif (2021) studied the Synthesis of Industrial Ceramic (Cordierite) from Iraqi Raw Materials Through Solid-State Sintering Method in Western Dessert used XRD for measuring the best mixture for preparing cordierite ceramics. The main objectives of this study are to find out the validity of the Injana, Mukdadiyah, and Bai Hassan formations, with Quaternary deposits for the ceramic industries, through the evaluation of the potential uses of their clays in some ceramic industries using mineralogical, chemical, and physical properties.

\section{Materials and Methods}

\subsection{Study Area}

The studied area covers about $800 \mathrm{Km}^{2}$ from Bestana to Gomaspan area (Fig. 1), east of Erbil city (NE of Iraq), with the nearest section including Mam-Choghan sample which is $23 \mathrm{~km}$ away from east of Erbil city, and the farthest section being Rasoul-Bchkol sample which is $38 \mathrm{Km}$ away from the east of Erbil city. The collecting of samples by channel sampling method from Injana, Mukdadiyah, Bai Hassan Formations and recent deposits in Bestana village (Table 1) recording longitude, latitude, and elevation by GPS.

Table 1. Coordination of studied samples using GPS (UTM) system with their symbols

\begin{tabular}{ccccccc}
\hline S. N & Name of sections & Symbols & Formations & Long. & Lat. & Elevation(m) \\
\hline 1 & Smaq-Shirin & SSH & Injana & 442066 & 4002481 & 697.2 \\
2 & Barda-Baz & BB & Mukdadiyah & 435449 & 4011618 & 534.2 \\
3 & Haji-Wusu & HW & Bai-Hassan & 439253 & 3998585 & 556.4 \\
4 & Mam-Choghan & MCH & Bai-Hassan & 428989 & 4008614 & 465.7 \\
5 & Rasoul-Bchkol & RB & Bai-Hassan & 432567 & 3987658 & 544.5 \\
6 & Bakhchay-Gawra & BG & Bai-Hassan & 432015 & 4008512 & 682.3 \\
7 & Bestana-Recent & B & Quaternary & 427959 & 3986007 & 578.3 \\
\hline
\end{tabular}

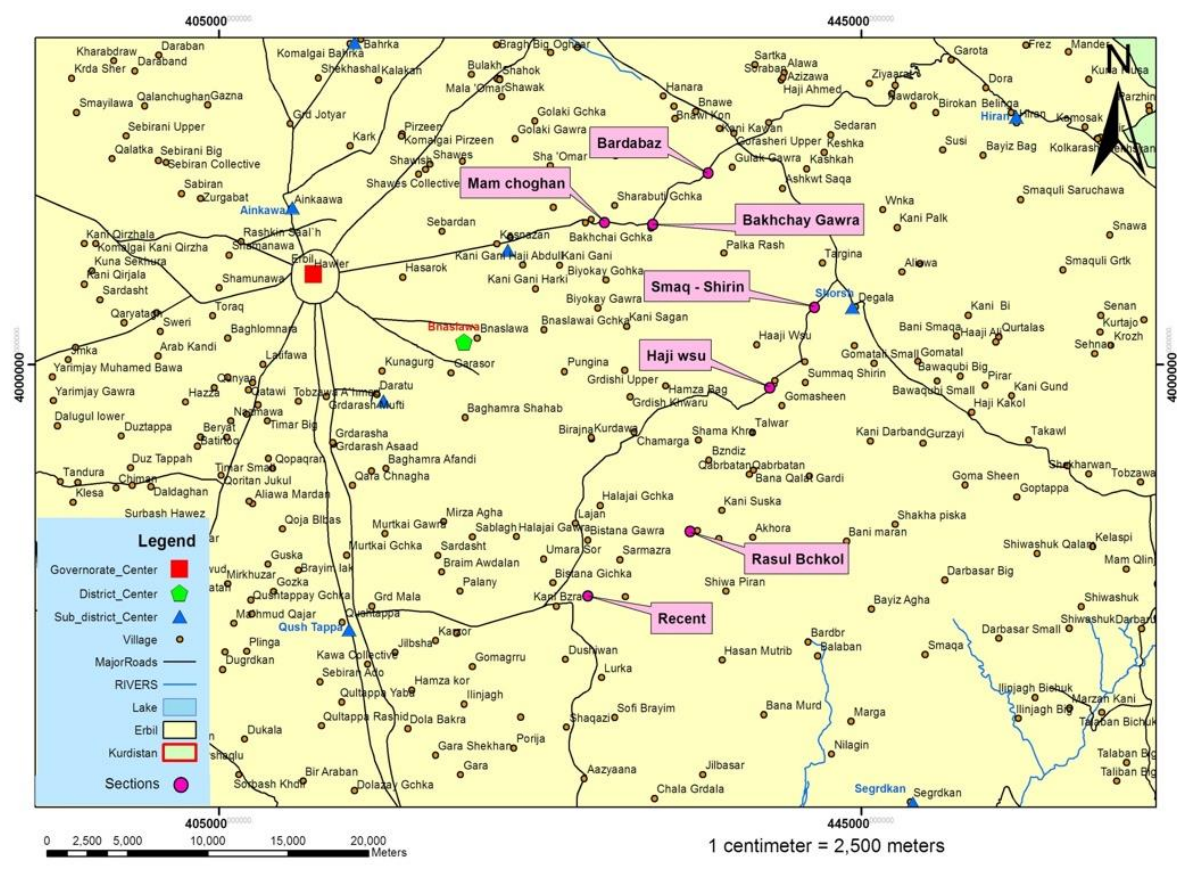

Fig. 1. Location map of the studied area and selected sections 


\subsection{Mineralogical Analysis of Raw Materials using XRD}

Clay minerals determined by XRD type (Phillps,1130) used in the Iraqi Geological surveyBaghdad, depending on the diffraction angle of each mineral, for this purpose the clay samples are ground to finer size $(<2 \mu \mathrm{m})$ separated from other sizes, and oriented smears were prepared by pipette method to obtain a good reflection by XRD technique (Friedman and Johnson, 1982). Then passing these slides through a diffractometer after various treatments such as solvation with ethylene glycol, and heating to a specified temperature at specified times under the following conditions: Detector speed $2 \theta$ $=2 \mathrm{~cm}, 2 \% \mathrm{~min}$, Current $(20 \mathrm{~mA})$, Voltage $(40 \mathrm{KV})$, Radiation tube $\mathrm{CuK} \alpha$, Filter element (Ni). The overlaps problem of some clay minerals has been solved by these methods according to Grim (1968), Carroll (1970), and Thorez (1976) in Hakeem (2012) as follows:

- Analyzing the first oriented smear by XRD without treatment including normal untreated (UN).

- The sample was exposed to the vapor for 24 hours of the reagent ethylene glycol solvation (Eg). It was dried in the oven at $60^{\circ} \mathrm{C}$ and then analyzed to determine the presence of montmorillonite, which is easily identified by comparing patterns of air-dried and ethylene glycol-solvated preparations. The glycol-treated preparations give a very strong 001 reflection at about 5.2-20 (16.9 $\AA$ ), which, in the air-dried condition shifts to about 6-20 (15 $)$ ), (Moore and Reynolds, 1989).

- Heating oriented smears to $550{ }^{\circ} \mathrm{C}$ for 2 hours, then analyzed by XRD, in this temperature the clay mineralogy structure will lose all of its water molecules content and destroy crystal structure in some of them. The XRF technique used to determine major oxides.

\subsection{Carbonate Mineral Quantity}

The carbonate mineral percentage in these studied samples were calculated according to Carver (1971), by using hydrochloric acid $\mathrm{HCl} 10 \%$ which was added to the pre-weighted samples and left for 24 hours to allow completing the reaction. Then the carbonate percentage calculated using the following equation: Carbonate $\%=$ weight loss/ weight of the sample* 100

\section{Geological Setting of the Area}

\subsection{Injana Formation}

Injana (Upper Fars) Formation (Late Miocene) covers the southern limb of Binabawi anticline, this formation consist of thick beds of red silty claystone between 3 to 20 meter and sandstone bed between 1.5 to 6 meters (Fig. 2), the overall thickness of the formation in this area is about $400 \mathrm{~m}$, the depositional environment of the Injana Formation is related to river (fluvial), flood plain (alluvial), and swamp (Al-Haidary, 2003), the upper contact is gradational with the Mukdadiyah Formation, and Smaq Shirin samples were taken from this formation.

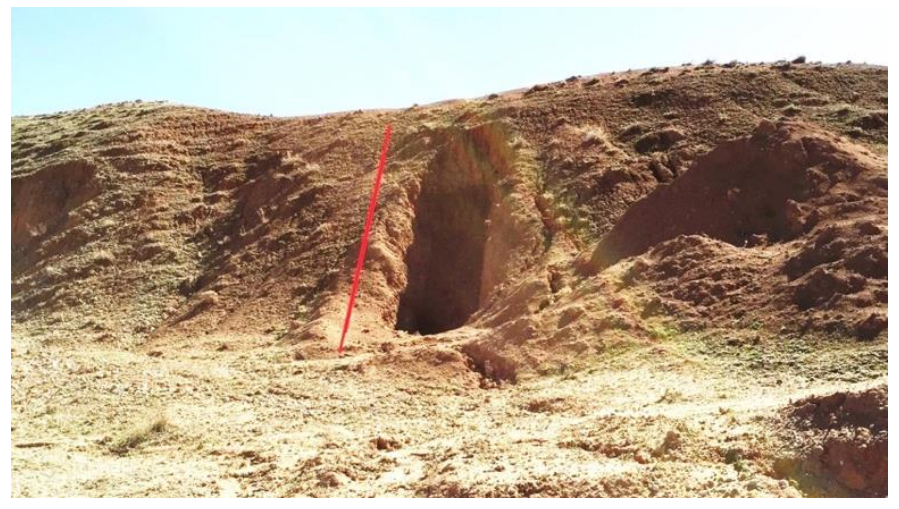

Fig. 2. Clay sample collected in the Injana Formation at Smaq Shirin village 


\subsection{Mukdadiyah Formation}

Mukdadiyah (Lower Bakhtiary) Formation (Early Pliocene) exposed in the larger part of the study area around Shalgha valley, lithologically, it is composed of pebbly sandstone of thickness 0.3 to $1 \mathrm{~m}$, thick layers of mudstone of thickness 4 to $45 \mathrm{~m}$. The overall thickness is about $650 \mathrm{~m}$. The depositional environment is fluvial and floods plain (Fig. 3). The upper contact is gradational with the Bai Hassan Formation, one of the studied sections including Barda Baz sample was taken from this formation.

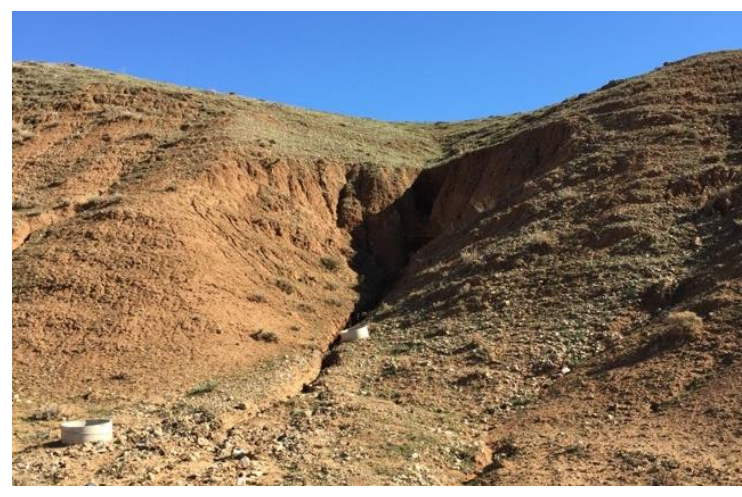

Fig. 3. Thick layer of clay in the Mukdadiyah Formation at Barda Baz village

\subsection{Bai Hassan Formation}

The Bai Hassan (Upper Bakhtiary) Formation (Late Pliocene) exposed at SW side of Shalgha valley, composed of light brown thick claystone with thickness 15 to $55 \mathrm{~m}$, with well-cemented large gravel conglomerate with thickness 1.5 to $6 \mathrm{~m}$, and some lens of sandstone. The overall thickness of this formation in the studied area is about $550 \mathrm{~m}$. The depositional environment of this formation is fluvial and flood plain (alluvial) (Fig. 4). The upper contact of this formation is unconformable with the Quaternary deposit, Haji Wusu, Rasoul Bchkol, Mam Choghan, Bakhchay Gawra samples were taken from this formation.

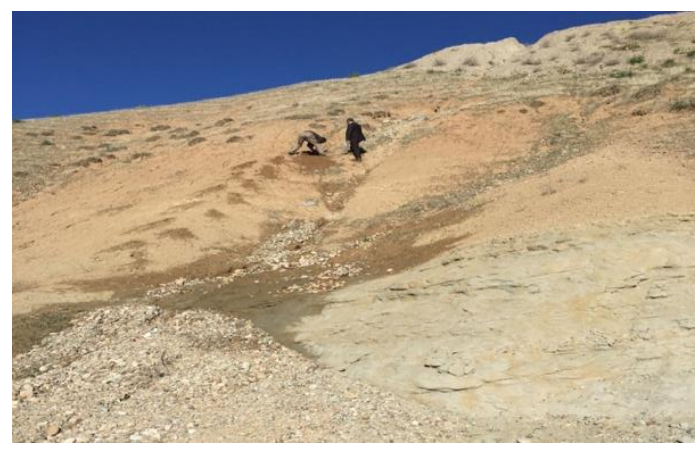

Fig. 4. Clay samples of Bai Hassan Formation at Bakhchay Gawra village

\subsection{Recent Deposit}

The Recent clay samples (Quaternary) in this study are located in Bestana village, lithologically, they are composed of alluvial deposits mixture of reddish-brown clay, silt and some debris of limestone. The rate of calcareous materials increases with the depth (Fig. 5), since they are washed by water and dropped downward. It was transported by rivers during flood where the stream distributed its sediments over the plain and deposited a large number of suspended sediments like clay, one sample taken from recent deposits including $\mathrm{R}$ sample. 


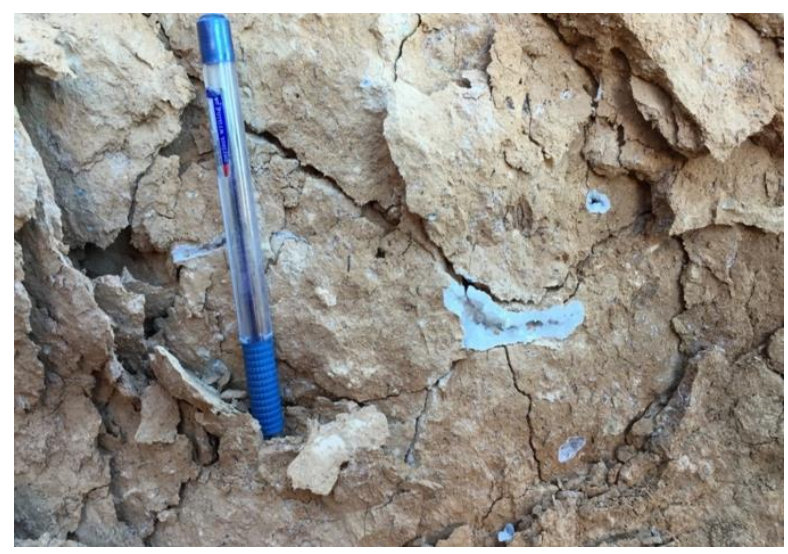

Fig. 5. Secondary calcite lens distributed in Quaternary deposits of Bestana village

\section{Clay Mineral Identification}

\subsection{Kaolinite}

Kaolinite is recognized by its basal reflections 001 and 002 which appears at $2 \theta 12.34$ and 24.88 which corresponds to d-spacing $7^{\circ} \mathrm{A}$ and $3.5^{\circ} \mathrm{A}$ respectively (Thorez, 1976). Kaolinite is non-hydrate and not affected by ethylene glycol treatment, due to the presence of strong bonds between the tetrahedral and octahedral layers (Carroll, 1970). At $550{ }^{\circ} \mathrm{C}$ a complete de-hydroxylation occurs and its structure collapses, which causes the peaks to disappear (Grim, 1968). Kaolinite has low drying and firing shrinkage, it's used in ceramic industries to optimize green strength, plasticity, and casting behavior (Ciullo, 1996).

\subsection{Illite}

Illite related to the mica-muscovite group, it is recognized by strong first order basal reflection $2 \theta$ of 8.84 which corresponds to $10^{\circ} \mathrm{A}(001)$ which remains unchanged after heating and ethylene glycol treatments (with exception of mixed-layer illite-smectite), due to the presence of potassium interlayer ions, which gives a strong bond and prevents swelling (Grim, 1968). Illite has also second order $2 \theta$ of 18.03 which corresponds to $4.9^{\circ} \mathrm{A}(002)$ reflection (Thorez, 1976), when illite is heated to $550^{\circ} \mathrm{C}$ its basal reflection intensity tends to increase, where some clay minerals such as smectite by heating also loses its interlayer water, then shifts to illite structure (Carroll, 1970; Pulkkinen, 2004). Illite has intermediate drying and firing shrinkage, it contributes to consistency and workability, smooth surface finish, and resistance to shrinkage and cracking in the ceramic industry use (Ciullo, 1996).

\subsection{Smectite}

Smectite is characterized by having greater than $50 \%$ octahedral charge, substitution in smectites occur mainly in the octahedral layer, resulting in charge deficiencies, which are neutralized by exchanging cations. Smectite is recognized by strong first order basal reflection at $2 \theta^{\circ} 5.95,6.5$ and 7.2 that corresponding to $\mathrm{d}$-spacing $14.98^{\circ} \mathrm{A}, 13.59^{\circ} \mathrm{A}$ and $12.27^{\circ} \mathrm{A}$ respectively, this referred to the difference in water molecules present in the structure of smectite $(\mathrm{OH})_{4} \mathrm{Al}_{4} \mathrm{Si}_{8} \mathrm{O}_{20} \cdot \mathrm{nH}_{2} \mathrm{O}$ (Bates, 1969). $\mathrm{X}$-ray patterns for smectite are generally of poor quality (Figs. 6,7,8 and 9), since the basal spacing varies with exchangeable cations, relative humidity, organic molecules and heat treatment on glycolation, (Thorez, 1976). The 001 is uniform nearly 17A, and reflections become rational and sharper, in 002 and 003 occur in 8.5A and 5.1A which is broad. All smectites may lose interlayer water at $100-200{ }^{\circ} \mathrm{C}$, yielding a collapsed structure with 9.6-10A (Thorez, 1976). Smectitic clays have high 
drying and firing shrinkage, smectite function in ceramic industries is to provide plasticity and green strength (Ciullo, 1996)

\subsection{Chlorite}

Chlorite rich in Fe provide relatively weak reflections at $2 \theta 6.32,18.80$, and 12.62 which corresponds to $14^{\circ} \mathrm{A}(001)$ and $4.7^{\circ} \mathrm{A}(003)$ and strong $7^{\circ} \mathrm{A}(002)$, (Thorez, 1976). Mg-rich chlorite provides a strong reflection at $13.6-14^{\circ} \mathrm{A}(001)$ and $7^{\circ} \mathrm{A}(002)$ and weak $3.5^{\circ} \mathrm{A}(004)$ reflection (Grim, 1968). Chlorite is not affected by ethylene glycol, but 001 may become more intense and shifts towards 13.6-13.8A, and have a broad peak of $2 \theta^{\circ}$ when heated at $550^{\circ} \mathrm{C}$ (Thorez, 1976), this evidence may not occur clearly in the studied samples due to the presence of a small amount of chlorite (Figs. 6,7,8 and 9), the intensity of 002 decreases, due to the loss of kaolinite mineral. Chlorite gives uniformity in chemical composition, (Table 2) hardness and fired shrinkage in ceramic industry (Ciullo, 1996).

\subsection{Mixed Layer Clay Mineral}

The irregular mixed layer clay mineral formed by random alteration of two or more clay minerals, forming an intermediate structure not a true mineral due to degradation by weathering or digenesis processes (Carroll, 1970), the intensity of the mixed minerals depends on the percentage of each of the two mixed minerals (Grim, 1968). the 001 basal reflections ranged between $2 \theta 5.90$ to 8.84 which corresponds to 10 to $15 \mathrm{~A}$ which refers to the presence of mixed layers of broad angles (Thorez, 1976), or due to the asymmetrical diffraction peaks of illite mineral, especially during ethylene glycol treatment. The 001 basal reflection of illite-smectite deviates towards $10 \mathrm{~A}$ by increasing illite mineral percentage in the mixed layer and vice versa, and the presence of some broad peaks in illite is due to the presence of small amount illite-smectite irregular mixed layer with illite mineral (Thorez, 1976).

\section{Non-Clay Mineral Identification}

\subsection{Quartz}

Quartz mineral specified under the XRD which have higher intensity under the angle $2 \theta$ (26.66) and lower intensity under the angle $2 \theta$ (20.8). It is the most abundant mineral among the non-clay minerals, quartz mineral found as a common mineral within all studied samples (Table 2). Quartz has a big role in the ceramic industry that decreases its plasticity, responsible for decreasing shrinkage and causes cracking of these ceramic bodies during dryness and firing, it causes viscous silica refractory material in higher temperatures (Rado, 1969). Its function in ceramic industries is to facilitate drying of the body to control expansion characteristics and compatibility between the body and glaze to prevent crazing, and to provide whiteness and acid resistance (Ciullo, 1996).

\subsection{Carbonate}

Carbonate minerals are present as calcite and dolomite minerals, calcite mineral occurs under XRD with high intensity at angle $2 \theta$ (29.4), and angle $2 \theta$ (23.04) with lower intensity, while the dolomite mineral specified under XRD with high intensity at angle $2 \theta$ (30.99), also these minerals represent the most abundant non-clay minerals. The high proportion of carbonate minerals during firing cause disintegration that results in a cracking body, fine grain carbonate mineral acts as a flux mineral that enhances reactions during firing and decreases refractory degree (Al-Kass et al. 1985) disintegration of carbonate minerals during firing increases porosity of the ceramic body and water absorption percent, and decreases its density if the pressing method didn't used. 


\subsection{Feldspar}

Feldspar groups occur under XRD with high- intensity diffraction angle $2 \theta$ (27.9) and with lower intensity in angle $2 \theta$ (25.3), (24.3), (23.5), and (13.8). Feldspar minerals act as a flux material in the ceramic industry (Shreve and Brink, 1977; Ryan, 1978) and causes vitrification with other minerals especially quartz, that causes melting in lower temperatures and continuous until becoming a viscous body, when cools down hardens and become a vitreous body results in strong hard ceramic body (AlHakeem, 1998). Feldspars are nearly as hard as quartz and are exploited for their chemistry in glassmaking and ceramics, since the aluminum content improves chemical and physical stability while its alkali content provides fluxing action with a high $\mathrm{K}: \mathrm{Na}$ ratios are generally preferred as fluxes in ceramic bodies to lower firing temperatures and allow faster firing schedules (Ciullo,1996).

\subsection{Dolomite and Hematite}

Dolomite mineral has high intensity at $2 \theta^{\circ} 31$ and is reflected in low intensity at $2 \theta^{\circ} 41.1$ and 45 . Hematite reflected at $2 \theta^{\circ} 33.6$ as high intensity and at $2 \theta^{\circ} 35.6$ as a low intensity, it acts as a flux material and responsible for the red color of the raw materials.

\section{Physical Properties of Raw Materials}

\subsection{Grain Size Analysis}

Grain size analysis represents the percentage of sand, silt, and clay in a given sample, it is known that finer particle size of clay means greater plasticity and greater capability reaction (Ryan, 1978), the finer particles increase the silica melt which binds these crystals together then become more coherent (Kingery, 1967; Rado, 1969). But higher sand content causes lower plasticity with a small surface area has fewer points of contact that require a high amount of water. These properties of clay affect the ceramic body during drying (green strength) and firing process (shrinkage after drying, compressive strength, and vitrification) (Rayn, 1978; Khalfaoui and Hajjaji, 2010). Both pipette and hydrometer analysis sorts clay particles by size using the physical process, when the particles are allowed to settle under gravity according to British Standard (BS 1377 - 1967), this test was carried out in College of Engineering Laboratory, Salahaddin University.

\subsection{Atterberg Limit}

The Atterberg limits are a basic measure of the critical water contents of a fine-grained soil, such as its plastic limit and liquid limit. Plasticity is an important property for ceramic industries because the paste with good plasticity is easy to work in terms of molding without the appearance of cracks (Grim, 1962), plasticity affected particle size and the typology of the clayey minerals, plasticity increased due to the clayey minerals in which the layers are weakly bound e.g; minerals of montmorillonite and/or illite nature, (Manfredini and Hanuskova, 2012). The water content which transfers the clays from one state to another is called Atterberg limits, (Krynine and Judd, 1957). Liquid limit is defined as the moisture content at which the clay passes from a plastic state to a liquid state; at this limit, the sample becomes a semi-fluid. Plastic limit is defined as the moisture content at which the clay passes from a plastic state to a brittle state; in this limit the samples begin to crumble when rolled into a $3 \mathrm{~mm}$ diameter thread, liquid limit is taken out by Casagrande device (Casagrande, 1958). These differences between the liquid and plastic limits are called "plasticity index" that is the range of moisture content in which clay is plastic. These limits vary according to the type and proportion of clay and non-clay minerals and their grain sizes (Gillot, 1968). The tests were carried out in the Department of Geology, College of Engineering, /Salahaddin University laboratories, according to B.S. 1377-1967. 


\subsection{Geochemical Characteristics of Raw Materials}

The geochemical characteristics have an important role in ceramic industries, and determination of the major oxide proportion of raw materials, help in understanding the behavior of ceramic body during firing, by estimation the flux and refractory oxides, as well as melting temperature. In addition to that, some oxides have an effect on the physical and mechanical properties of ceramic product (Shreve and Brink, 1977), hence the chemical analysis data would give an idea about any characteristics which influences to great extent the suitability of the clays used for application in ceramic industry and precaution informing and firing. Flux creates a limited and controlled amount of glass in ceramic bodies, which works to connect crystalline components together. Fluxes play a key role in the vitrification of clay bodies by reducing the overall melting point. Common fluxes in clay are; $\mathrm{K}_{2} \mathrm{O}, \mathrm{Na}_{2} \mathrm{O}, \mathrm{CaO}, \mathrm{MgO}$, and $\mathrm{Fe}_{2} \mathrm{O}_{3}$ (Riley, 1951; Rattanachan and Lorprayoon, 2005; Fakhfakh et al., 2007), if the refractory minerals increased it will increase the melting temperature. Common refractory materials in clay are; $\mathrm{Al}_{2} \mathrm{O}_{3}, \mathrm{SiO}_{2}, \mathrm{MgCO}_{3}$, and $\mathrm{Cr}_{2} \mathrm{O}_{3}$ (Table 9) they are carried out by $\mathrm{X}$-ray fluorescence in the laboratories of the Iraqi Geological Survey, Baghdad.

\section{Results and Discussion}

\subsection{Clay Mineral Identification}

The clay mineral identification by XRD within all of the studied raw materials are represented by a major proportion of kaolinite and a minor proportion of illite, smectite and illite- smectite mixed layer with few proportions of chlorite (Table 2). Each clay particle has an important influence on the ceramic properties, while in ceramic industries they have appropriate properties which make them suitable for giving plasticity, moldable when wet, hard when dried and vitrified when fired (Kingery, 1967). Kaolinite mineral found as a common mineral in SSH and R sample, and as a secondary mineral in BB and BG samples (Figs. 6,7,8, and 9). Illite is found as a common mineral in SSH samples, and as a secondary mineral in R and BB (Figs. 6,7, and 8), with exception of BG that is present as an irregular mixed layer with smectite, and this is shown by an asymmetry of illite peak to low angle side (Fig. 9). Smectite found as a rare mineral within all of the samples, and mixed layer with chlorite in all four samples except in BG were found as a mixed layer with illite too. Chlorite is found as rare mineral and a mixed layer with smectite in all of the samples. In the studied samples, the irregular mixed layer between chlorite and smectite found within all four samples (Figs. 6,7,8 and 9), that characterized by irrational series of higher order reflections, but in 003 reflection there is chlorite as a single mineral, and between illite and smectite found only in BG (Fig. 9).

\subsection{Non-Clay Mineral Identification}

Quartz and calcium carbonate minerals are present in the clay samples as common minerals. Quartz content leads to vitrification and quartz phase transformation causes shrinkage decrease at higher temperatures, which act as a refractory material. Quartz was found to be of a higher proportion than calcite in R and SSH samples (Figs. 6 and 8), and a lower proportion than calcite in BB and BG samples (Figs. 7 and 9). Calcite found as a common mineral in all studied samples. The decomposition of the carbonate minerals during firing will also increase the porosity and decrease the bulk density of the ceramic body. The percentage of carbonate minerals in the all studied samples ranges between 9.31 to $24.13 \%$ (Table 3 ). This percentage is suitable for ceramic industries especially for construction products like brick, because clays will become unsuitable for ceramic industries if the carbonate percentage exceeds $30 \%$ according to Thanoon (2013) exceeds 35\% according to Al-Dwaf (1969). In the studied samples feldspar found as a secondary mineral in BB sample (Fig. 7) (Table 2) and rare mineral in SSH and BG samples (Figs. 8, and 9), but its absent in R sample. Dolomite found as a secondary mineral in 
BB sample (Fig. 7), and rare minerals in SSH, R, and BG samples. Hematite found as a rare mineral in all samples (Figs. 6,7,8 and 9).

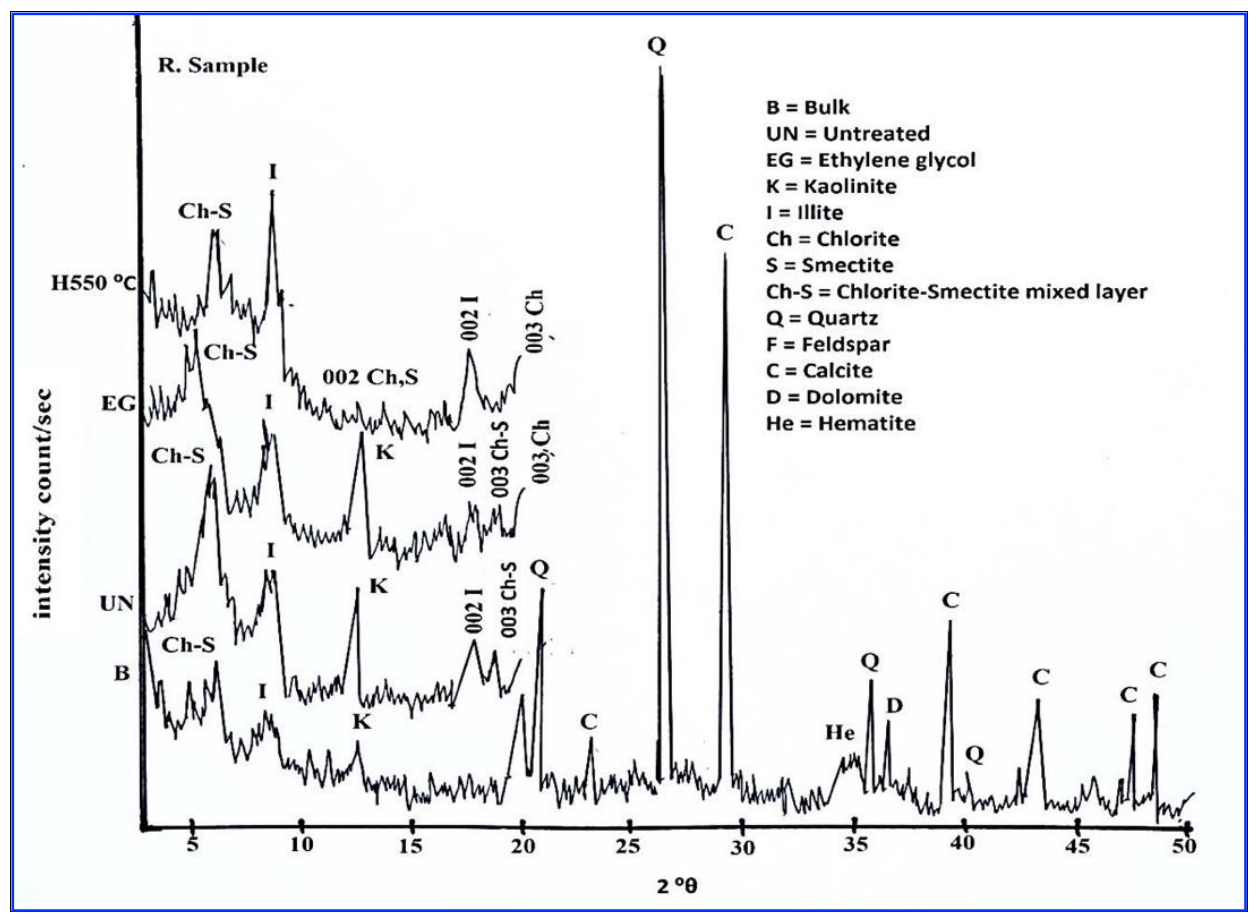

Fig. 6. X-ray diffractograms of channel sample from R sample

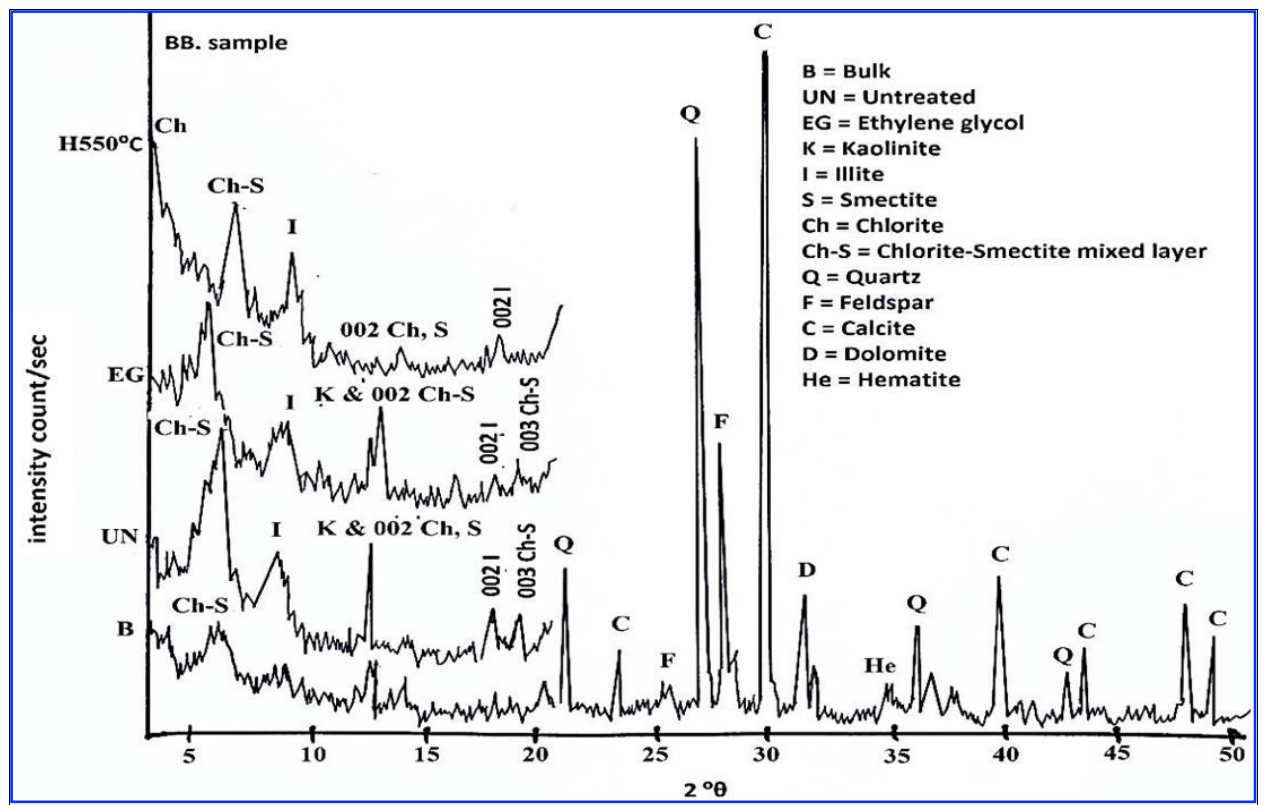

Fig. 7. X-ray diffractograms of channel sample from BB sample 


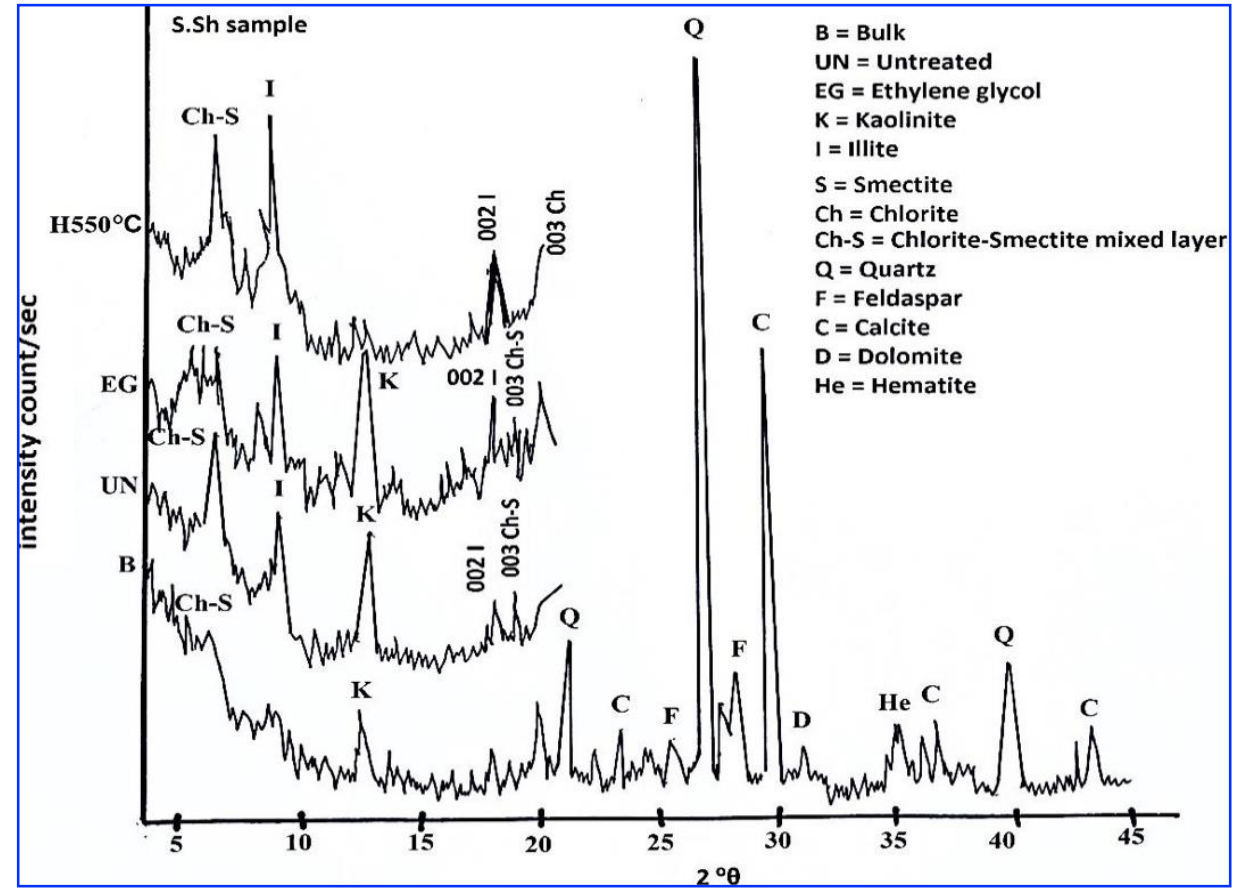

Fig. 8. X-ray diffractograms of channel sample from SSH sample.

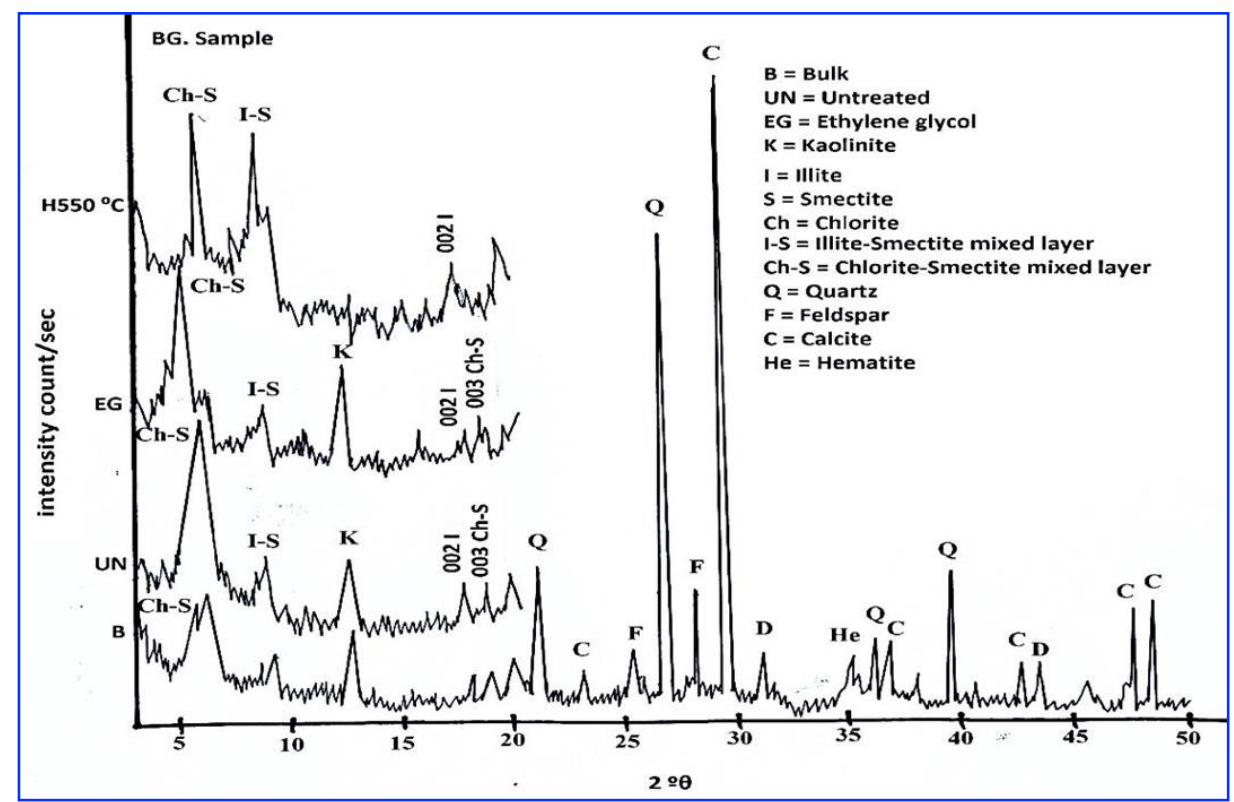

Fig. 9. X-ray diffractograms of channel sample from BG sample

Table 2. Relative abundance of clay and non-clay minerals in the studied samples

Sample Montmorillonite Kaolinite Chlorite Quartz Calcite Dolomite Feldspar Hematite

\begin{tabular}{|c|c|c|c|c|c|c|c|c|}
\hline $\mathrm{SSH}$ & $*$ & $* * *$ & $*$ & $* * *$ & $* *$ & $*$ & $*$ & $*$ \\
\hline $\mathrm{R}$ & $*$ & $* * *$ & $*$ & $* * *$ & $* *$ & $*$ & $\ldots$. & $*$ \\
\hline BB & $* *$ & $* *$ & $* *$ & $* *$ & $* * *$ & $* *$ & $* *$ & $*$ \\
\hline $\mathrm{BG}$ & $* *$ & $* *$ & $* *$ & $* *$ & $* * *$ & $*$ & $*$ & $*$ \\
\hline
\end{tabular}


Table 3. Carbonate mineral percentages in the studied samples.

\begin{tabular}{cc}
\hline Sample & Carbonate \% \\
\hline SSH & 15.67 \\
HW & 9.31 \\
R & 24.13 \\
RB & 12.23 \\
BG & 19.44 \\
BB & 23.89 \\
MCH & 11.56 \\
\hline
\end{tabular}

\subsection{Grain Size Analysis}

The results of the grain size analysis of both pipette and hydrometer methods showed that the seven raw materials are composed mainly of clay $(<4 \mu \mathrm{m})$ and silt $(4-63 \mu \mathrm{m})$ portions, with a minor amount of sand ( $63 \mu \mathrm{m}-2 \mathrm{~mm})$ (Tables 4 and 5). There are slight differences between these two methods, with clay proportion being higher in hydrometer method than pipette method in contrast to sand proportion. HW sample have the highest clay proportion among them, while RB sample has the highest silt proportion, and BG sample has highest sand proportions in both methods. Folk (1980) classification triangle for both pipette and hydrometer method plotted and all samples carried out by pipette method located on the sandy mud field (Figs. 10 and 11), whereas by hydrometer method located on the mud field.

Table 4. Grain size analysis by pipette method for the studied samples

\begin{tabular}{lccc}
\hline Sample & Sand \% & Silt \% & Clay \% \\
\hline SSH & 10.2 & 59.6 & 30.2 \\
HW & 10 & 47.2 & 42.8 \\
RB & 12.5 & 58.6 & 28.9 \\
R & 10.4 & 58.7 & 30.9 \\
BG & 13.1 & 50.7 & 36.2 \\
MCH & 11 & 56.6 & 32.4 \\
BB & 13 & 58 & 29 \\
\hline
\end{tabular}

Table 5. Grain size analysis by hydrometer method for the studied samples

\begin{tabular}{lccc}
\hline Sample & Sand \% & Silt \% & Clay \% \\
\hline SSH & 8.1 & 56.3 & 35.6 \\
HW & 8 & 44.4 & 47.6 \\
RB & 9.5 & 59.5 & 31 \\
R & 8.5 & 59 & 32.5 \\
BG & 9.7 & 46.9 & 43.3 \\
MCH & 8.7 & 56.5 & 34.8 \\
BB & 9.6 & 59 & 31.4 \\
\hline
\end{tabular}




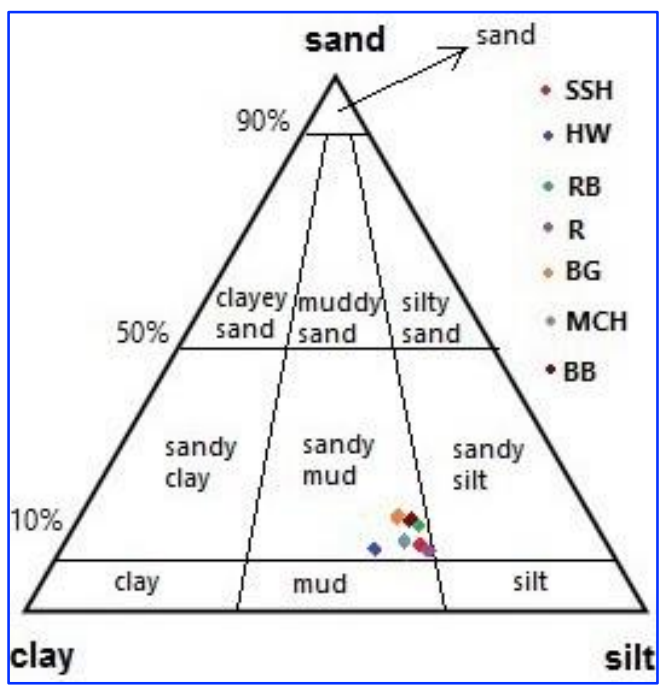

Fig. 10. Relative distribution of sand, silt, and clay portions by pipette method (Folk, 1980).

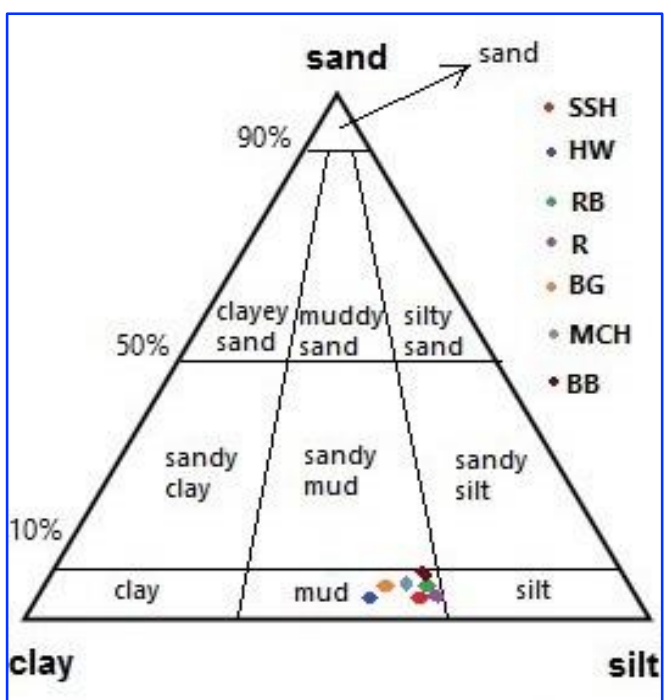

Fig. 11. Relative distribution of sand, silt, and clay portions by hydrometer method (Folk, 1980)

In order to find out the suitability of these studied samples for roofing tile and different types of brick, results of these analyses were plotted on the triangle diagram, which divides the samples into three different sizes (less than $2 \mu \mathrm{m}, 2-20 \mu \mathrm{m}$, and more than $20 \mu \mathrm{m}$ ) as shown in Table 6 by using the pipette method. According to this classification all of the studied samples can be used in solid brick, lattice brick, and roofing tile industries (Fig. 12) except SSH and HW samples which can be used in the hollow brick industry too.

Table 6. Grain size analysis of the studied samples for their use in brick and tile industries

\begin{tabular}{|c|c|c|c|}
\hline Sample & $<2 \mu \mathrm{m} \%$ & $2-20 \mu \mathrm{m} \%$ & $>20 \mu \mathrm{m} \%$ \\
\hline $\mathrm{HW}$ & 34.18 & 37.22 & 28.6 \\
\hline SSH & 42.31 & 38.1 & 19.59 \\
\hline $\mathrm{RB}$ & 33.4 & 31.09 & 33.51 \\
\hline $\mathrm{R}$ & 32.83 & 38.8 & 28.37 \\
\hline $\mathrm{MCH}$ & 39.13 & 27.63 & 33.24 \\
\hline $\mathrm{BB}$ & 36.1 & 23.55 & 40.35 \\
\hline $\mathrm{BG}$ & 32.34 & 31.14 & 35.52 \\
\hline
\end{tabular}




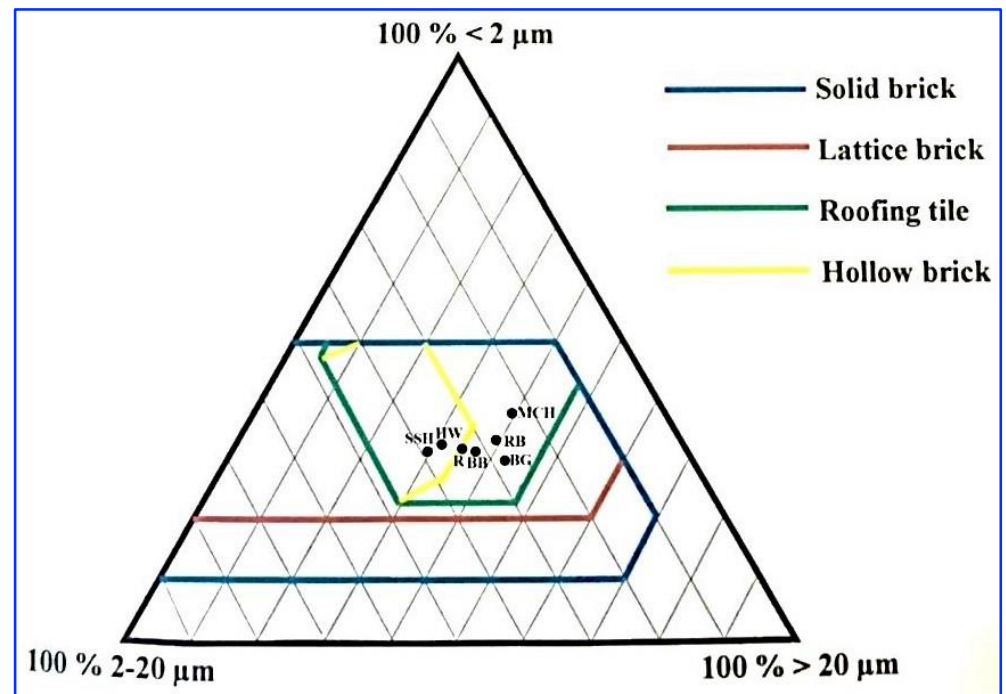

Fig. 12. Suitability of the studied samples for roofing tile and different types of brick (Hakeem, 2012)

\subsection{Atterberg Limits}

Atterberg limits, plastic limit, liquid limit, and plasticity index are calculated, Table 7 shows the results of these tests. The plastic limit ranges from 17.24 to $24.55 \%$, The low plasticity of R, BB, and $\mathrm{RB}$ samples are due to the high percentage of silt and low percentage of clay in addition to the presence of sand. Grimshaw (1971) prescribed the range of plastic limit as $10-60 \%$ for clay used in ceramic production, depending on this range and on the results of plastic limit percentage (Table 7), all samples are suitable for ceramic production. The liquid limit ranges from 30 to $47 \%$, and the plasticity index ranges from 12.76 to 22.45. The higher limits of plasticity in the $\mathrm{HW}, \mathrm{BG}, \mathrm{SSH}$, and $\mathrm{MCH}$ samples are due to their high proportion of clay. Depending on the plasticity index, and according to Budnikov (1964) classification (Table 8), the studied samples are classified as plastic and moderately plastic.

Table 7. Atterberg limits for the studied samples

\begin{tabular}{lccc}
\hline Sample & Plastic limit\% & Liquid limit \% & Plasticity index\% \\
\hline HW & 24.55 & 47 & 22.45 \\
BG & 24.48 & 46 & 21.51 \\
SSH & 22.88 & 43 & 20.11 \\
MCH & 20.47 & 36 & 15.53 \\
R & 19.92 & 34 & 14.08 \\
BB & 18.01 & 31 & 12.99 \\
RB & 17.24 & 30 & 12.76 \\
\hline
\end{tabular}

Table 8. Determining the plasticity of the studied samples, according to Budnikov (1964)

\begin{tabular}{lcc}
\hline Classification & Plasticity index & Sample \\
\hline Super plastic & More than 25 & - \\
Plastic & $15-25$ & HW, BG, SSH, MCH \\
Moderately plastic & $7-15$ & R, BB, RB \\
Poorly plastic & Less than 7 & - \\
Non plastic & Not forming plastic mass & - \\
\hline
\end{tabular}


Fig. 13 shows the positions of the studied samples on the clay workability sketch, depending on the plastic limit and plasticity index. This sketch shows that all of the studied samples are suitable for the brick industry, while only SSH, BG, and HW samples are suitable for pottery industries too, which have a high plastic limit, due to high silt and clay content. But MCH, R, BB, and RB show a trend towards poor coherence due to low silt and clay content. Therefore, they may need to be improved by adding materials like fine sand or silt to decrease their linear shrinkage (Aqrawi, 2009).

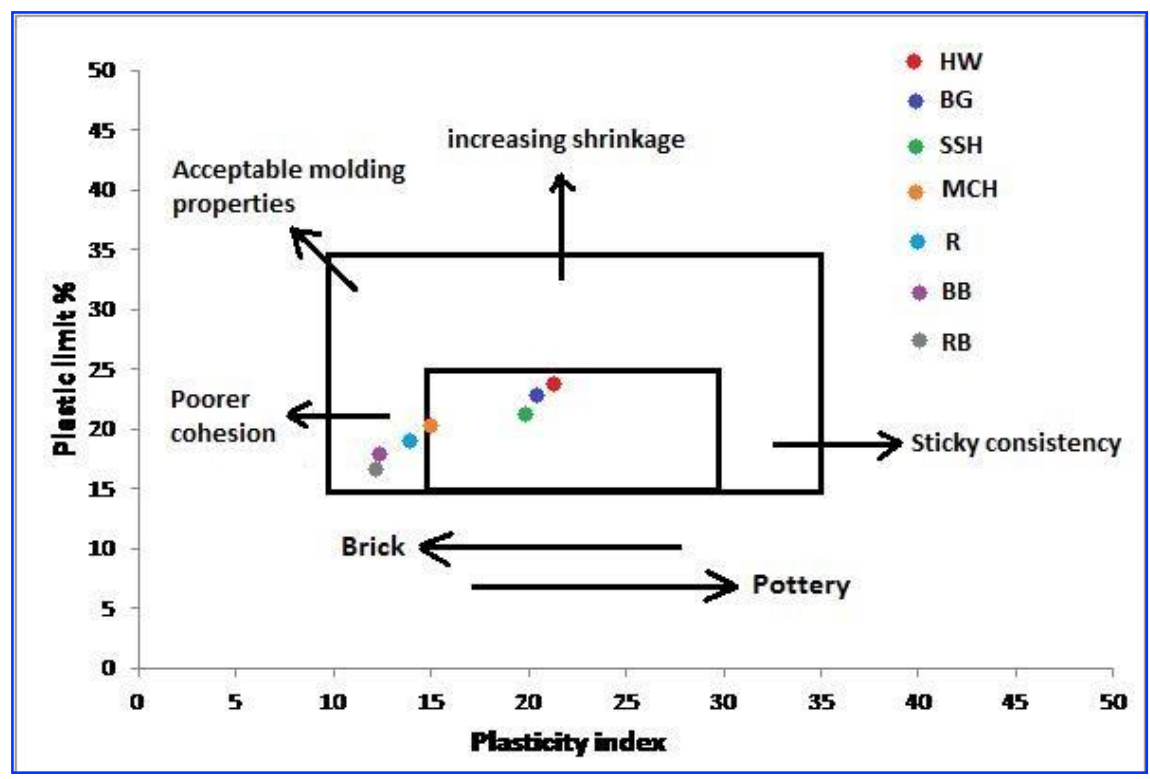

Fig.13. Clay workability sketch (after Bain and Highley, 1978) for the studied samples

\subsection{Geochemical Characteristics of Raw Materials}

The results of geochemical analysis are shown in Table 9 for SSH sample in the Injana Formation, BB sample in the Mukdadiyah Formation, HW, and BG in Bai Hassan Formation, and R in Quaternary deposits. It shows that the raw materials are composed essentially of silica ranging between 35.15 to $44.05 \%$. Silica is important for controlling the firing shrinkage that provides densification of the ceramic product (Aqrawi, 2009).

The calcium oxide ranges from 9.97 to $16.55 \%$ due to the presence of calcite in the raw materials of all studied samples (Figs. 6,7,8 and 9), this oxide acts as a flux that affects the formation of the liquid phase at a relatively high temperature (Aqrawi, 2000) and used as one of the methods for controlling the firing shrinkage and water absorption (Das et al., 2005). It also provides the densification of the ceramic body at high firing temperatures. Alumina is of a considerable proportion ranging between 12.85 and $15.89 \%$ in the studied samples. Alumina and silica act as refractory oxides in ceramic industries that lead to decreasing of the liquid phase, linear shrinkage, total density and increasing of apparent porosity, and water absorption (Aqrawi, 2009). The magnesium oxide $(\mathrm{MgO})$ ranges between $5.01-5.91 \%$ that refers to the clay minerals especially smectite and chlorite but the high proportion was observed in BB section (Table 9) due to the considerable amount of dolomite mineral in this sample. Magnesium also participates in the structure of clay minerals, according to Medhioub et al. (2010). MgO acts as sintering promoters on the vitrification. The total $\mathrm{MgO}$ and $\mathrm{CaO}$ content in all clay samples ranges between 5.01 and $16.55 \%$ which has a bleaching effect on the fired clay especially when vitrification is very low. Chlorite salt is present as $\mathrm{Cl} . \mathrm{Na}_{2} \mathrm{O}$ and $\mathrm{SO}_{3}$ represent the presence of sodium sulfate salts, which causes efflorescence on the brick surface.

Iron oxide ranges between 6.38 to $8.02 \%$, being responsible for the reddish color after firing (Faraj, 2014). On the other hand, iron oxide with other fluxes increase the chance to form a considerable 
amount of liquid phase at a relatively low firing temperature that accelerates the vitrification (Gonzalez et al., 1998; Medhioub et al., 2010). Other oxides of $\mathrm{MgO}, \mathrm{Na}_{2} \mathrm{O}$, and $\mathrm{K}_{2} \mathrm{O}$ show the minor amount, $\left(\mathrm{Fe}_{2} \mathrm{O}_{3}, \mathrm{CaO}, \mathrm{MgO}, \mathrm{K}_{2} \mathrm{O}\right.$, and $\left.\mathrm{Na}_{2} \mathrm{O}\right)$ are considered as fluxing materials in the ceramic industries. Loss on ignition was calculated during firing at $1000{ }^{\circ} \mathrm{C}$ and ranges between 15.08 to $20.72 \%$, the considerable amount of Loss On Ignition (L.O.I) is due to the decomposition of carbonate minerals and escaping of the $\mathrm{CO}_{2}$ gas, as well as the molecular and adsorbed water present in and on the crystal structure of the clay minerals (Hakeem, 2012).

Table 9. Chemical analysis for studied raw materials.

\begin{tabular}{lccccc}
\hline Oxides \% & BG & BB & SSH & R & HW \\
\hline $\mathrm{SiO} 2$ & 37.64 & 35.15 & 41.7 & 44.05 & 42.31 \\
$\mathrm{Fe} 2 \mathrm{O} 3$ & 6.63 & 6.38 & 8.02 & 6.63 & 6.84 \\
$\mathrm{Al} 2 \mathrm{O} 3$ & 13.79 & 12.96 & 15.89 & 13.32 & 12.85 \\
$\mathrm{CaO}$ & 14.54 & 16.55 & 9.97 & 11.33 & 12.92 \\
$\mathrm{MgO}$ & 5.57 & 5.91 & 5.54 & 5.01 & 5.79 \\
$\mathrm{Na} 2 \mathrm{O}$ & 0.19 & 0.22 & 0.37 & 0.1 & 0.37 \\
$\mathrm{~K} 2 \mathrm{O}$ & 1.43 & 1.34 & 2.85 & 1.96 & 2.01 \\
$\mathrm{SO} 3$ & 0.03 & 0.04 & 0.04 & 0.04 & 0.07 \\
$\mathrm{CL}$ & $<0.02$ & $<0.02$ & $<0.02$ & $<0.02$ & $<0.02$ \\
L.O.I. & 19.47 & 20.72 & 15.08 & 16.83 & 16.13 \\
Total & 99.31 & 99.29 & 99.48 & 99.29 & 100.01 \\
\hline
\end{tabular}

\section{Conclusions}

- The mineralogical analysis of the studied clay samples reveals that SSH and R samples contain higher amounts of kaolinite and illite clay minerals, with quartz non-clay mineral, in contrast to BB and BG samples contain higher amounts of smectite and chlorite clay minerals with calcite nonclay mineral.

- The physical properties of the raw materials in terms of the grain size distribution of the studied samples by hydrometer method are more accurate since it measures density and temperature of suspension, which is not included in the pipette method, the samples are classified as mud in hydrometer method while in pipette method the samples are classified as sandy mud. Evaluation of the studied samples according to grain size analysis, shows that all of the studied samples can be used for solid brick, lattice brick, and roofing tile, with HW, and SSH samples can be used in the hollow brick industry too.

- The physical properties of raw materials in terms of plasticity index of the studied samples shows that $\mathrm{HW}, \mathrm{BG}, \mathrm{SSH}$, and $\mathrm{MCH}$ samples are plastic due to high clay content in contrast to R, BB, and RB samples which have moderate plasticity due to lesser clay content, while SSH and R samples located in between plastic to moderately plastic, since these two samples contain high illite and smectite, which helps to give them plasticity, and high quartz content that decreases their plasticity at the same time.

\section{Acknowledgements}

The authors are very grateful to the Editor in Chief Prof. Dr. Salih M. Awadh, the Secretary of Journal Mr. Samir R. Hijab. and the Technical Editors for their great efforts and valuable comments. 


\section{References}

Al-Dwaf, Y., 1969. Building and Construction Materials. Baghdad, 393 pp (In Arabic).

Al-Haidary, S., 2003. Sedimentological Study of Injana Formation in Erbil Governorate. Unpublished M.Sc. Thesis, University of Salahaddin, $124 \mathrm{pp}$ (In Arabic).

Al-Hakeem, F.A., 1998. Assessment of Some Neogene Clay from North of Iraq for Ceramic. Unpublished M.Sc. Thesis, University of Baghdad, 100 p. (In Arabic).

Al-Kass. R.M., Hadi, M.A., Khalil, N.I., Al-Takarli, S.F., 1985. Effect of calcite grains present in the soil on the properties of clay brick, Building Research Center, Baghdad, Iraq, 53 pp.

Aqrawi, A. M., 2009. Improvement of clay utilized by the Duhok brick factory, Duhok, Iraqi Kurdistan Region. Zanco, Journal of Pure and Applied Science, Salahaddin University-Hawler, 21(1), 139-157.

Aqrawi, A.M., 2000. Assessment of Iraqi Serpentinites for Utilization in Ceramics, Ph.D Thesis, University of Baghdad, 220 pp.

Awad, A.M. and Awadh, S.M. 2020. Reserve estimation of Late Miocene Injana claystone beds for portland cement and brick industry, Middle of Iraq. Iraqi Geological Journal, 53 (1D), 1-16.

Awad, A.M. and Awadh, S.M. 2021. Manufacturing perforated and ordinary bricks using Injana claystone in Middle of Iraq, Iraqi Geological Journal, 54 (1A) ,11-22.

Awadh, S.M. and Al-Owaidi, M.R., 2020. Application of triangles method for quantitative estimation of marl reserve in Euphrates formation, middle of Iraq. The Iraqi Geological Journal,.35-49.

Awadh, S.M. and Awad, A.M., 2021. Evaluation of the Injana claystone from Central Iraq for the brick industry. Kuwait Journal of Science, 48(2).

Bain, J. A. and Highley, D.E., 1978. Regional appraisal of Clay resources a challenge to the clay mineralogist. Proceeding International clay conference, Oxford, 437-446.

Bates, R.L., 1969. Geology of the Industrial Rocks and Minerals, Dover Publications, INC., New York, 459pp.

Budnikov, P.P., 1964. The technology of ceramics and refractories, Massachusetts Institute of Technology, Cambridge, 647pp.

Carroll, D., 1970. Clay minerals: A guide to their X- Ray identification, The Geological Society of America, 80 pp.

Carver, R.E., 1971. Procedure in sedimentary petrology. John Wiley and Sons Inc., New York, 653 pp.

Casagrande, A., 1958. Notes on the design of the liquid limit device Geotechnique, 8, 2: 84-91.

Ciullo, P. A., 1996. Industrial minerals and their uses" Published in the United States of America, Noyes Publications, $443 \mathrm{pp}$.

Das, S. K., Dana, K., Singh, N., and Sarkar, R., 2005. Shrinkage and strength behavior of quartzitic and kaolinitic clays in wall tile compositions, Applied Clay Science, 29, 137-143.

Fakhfakh, E., Hajjaji, W., and Medhioub, M., 2007). Effects of sand addition on production of light weight aggregate from Tunisian smectite-rich clayey rocks, Applied Clay Science, 35, 228-237.

Folk, R.L., 1980. Petrology of Sedimentary Rocks. Hemphill publishing company, Austin, Texas, 184pp.

Friedman, G., Johnson, K.G., 1982. Exercises in sedimentology. John. Wiley and Sons, New York, 208 pp.

Gillot, J. E., 1968. Clay in Engineering Geology. Elsevier Publications Company, 296 pp.

Gonzalez, I, Galan, E., MiRas, A., and Aparicio, P., 1998. New uses for Brick-making clay materials from the Bailen area (Southern Spain), Clay Minerals, 33, 453-465.

Grim, R.E., 1962. Applied Clay Mineralogy, 20, McGraw-Hill, Book Co. Inc. New York, 422pp.

Grim, R.E., 1968. Clay Mineralogy. $2^{\text {nd }}$ edition, MCG raw-Hill, New York, 596pp.

Grimshaw, R.W., 1971. The Chemistry and Physics of Clays and Allied Ceramic Materials, $4^{\text {th }}$ edition. Erenest Benn, London, 1024pp.

Hakeem, F.A., 2012. Sedimentology and Suitability for Some Ceramic Industries of Beduh Formation (Lower Triassic), Northern Thrust Zone, Kurdistan Region-Iraq", unpublished Ph.D. dissertation, University of Salahaddin, $177 \mathrm{pp}$.

Khalfaoui, A., and Hajjaji, M., 2010. Assessment of the ceramic suitability of a Raw Clay, Ceramics -Silikaty 54(4), 295-302.

Kingery, W.D., 1967. Introduction to Ceramics. John Wiley and Sons, New York.

Manfredini, T., and Hanuskova, M., 2012. Natural raw materials in traditional ceramic manufacturing, Journal of the University of Chemical Technology and Metallurgy, 47(4), 465-470. 
Medhioub, M., Baccour, H., Jamoussi, F. and Mhiri, T., 2010. Composition and ceramic properties of Triassic clays from Tunisia, Journal of Ceramic Processing Research, 11(2), 209-214.

Moore \& Reynolds, 1989. Quantitative X-Ray diffraction analysis of clay-bearing rocks from random preparations, Clays and Clay Minerals, 49 (6), 514-528.

Najim, M.M., and Yousif, B.A., 2021. Synthesis of industrial ceramic (cordierite) from Iraqi raw materials through solid-state sintering method. Iraqi Geological Journal, 54 (1A), 23-34.

Pulkkinen, P., 2004. Mineralogy and Geochemistry of the Fine and the Clay Fractions of Till in Northern Finland. Report, Oulu University Press, Finland, 190 pp.

Rado, P., 1969. An Introduction to the Technology of Pottery. Pregmon Press, Oxford, 258 pp.

Rattanachan, S., and Lorprayoon, C., 2005. Korat clays as raw materials for light weight aggregates, Journal Science Asia, 31, 277-281.

Riley, C.M., 1951.Relation of chemical properties to the bloating of clays, Journal American Ceramic Society, 34 , 121-128.

Ryan, W., 1978. Properties of Ceramic raw materials, $2^{\text {nd }}$ edition. Pergamon Press, Oxford, 113pp.

Shreve, R.N., and Brink, J.A., 1977. Chemical Process Industries, McGraw-Hill, Kogakusha, Ltd, 814pp.

Thanoon, A.T., 2013. Industrial Rocks and Minerals. Dar Ibn Al-Atheer for Printing and Publishing, University of Mosul, 240, (In Arabic).

Thorez, J., 1976. Praactical Identification of Clay Minerals. Edit. G. Lelottc, Belgium, 89 pp. 